\title{
Educação corporativa: aprendizagem significativa no âmbito das empresas
}

\section{Corporate education: meaningful learning in the context of companies}

\section{Educación corporativa: aprendizaje significativo en el contexto de} empresas

Celi Langhi ${ }^{1}$; Denilson de Sousa Cordeiro ${ }^{2}$; Mariana de Lima Simões 3 ; Caio Flávio Stettiner ${ }^{4}$

\section{RESUMO}

As empresas brasileiras têm efetuado investimentos em educação para superarem crises, para adquirirem competividade para lidar com os desafios da economia atual e para alcançarem seus objetivos estratégicos. Este artigo tem como objetivo discutir a aplicação da teoria da aprendizagem significativa para o desenvolvimento de boas práticas de ensino na educação corporativa. Foi realizada uma pesquisa qualitativa, com base na revisão descritiva da literatura, a qual revelou estruturas e tendências a respeito da aplicabilidade dos pressupostos teóricos da aprendizagem significativa nos processos de ensino e aprendizagem nas empresas. Os resultados indicam que, para que ocorra aprendizagem significativa na educação corporativa, é necessário que os processos didáticos nas empresas sejam mais inclusivos em relação a novos conhecimentos, considerando a importância dos conhecimentos prévios dos indivíduos.

Palavras-chave: Educação corporativa; Aprendizagem significativa; Estrutura cognitiva; Conhecimentos prévios.

\begin{abstract}
Brazilian companies have made investments in education to overcome crises, to acquire competitiveness to deal with the challenges of the current economy and to achieve their strategic objectives. This article aims to discuss the application of the theory of meaningful learning to the development of good teaching practices in corporate education. A qualitative research was carried out, based on the descriptive literature review, which revealed structures and trends regarding the applicability of the theoretical assumptions of meaningful learning in the teaching and learning processes in companies. The results indicate that, for meaningful learning to occur in corporate education, it is necessary that the didactic processes in companies are more inclusive in relation to new knowledge, considering the importance of the individuals previous knowledge.
\end{abstract}

Keywords: Corporate education; Meaningful learning; Cognitive structure; Previous knowledge.

\footnotetext{
${ }^{1}$ Doutora e Mestre em Psicologia. Professora do Programa de Mestrado do CEETEPS, Unidade de PósGraduação, Extensão e Pesquisa, São Paulo/SP - Brasil. E-mail: celi.langhi@cps.sp.gov.br

2 Mestrando do Programa de Mestrado do CEETEPS, Unidade de Pós-Graduação, Extensão e Pesquisa, São Paulo/SP - Brasil. E-mail: cordeiro@gmail.com

${ }^{3}$ Mestranda em Políticas Públicas pela Universidade Estadual do Ceará (UECE), Fortaleza/CE - Brasil. E-mail: mariana.Isimoes@gmail.com

${ }^{4}$ Mestre em Educação e Professor da Fatec Sebrae, São Paulo/SP - Brasil. E-mail: stettiner.caio@gmail.com
} 


\section{RESUMEN}

Las empresas brasileñas han realizado inversiones en educación para superar crisis, adquirir competitividad para enfrentar los desafíos de la economía actual y alcanzar sus metas estratégicas. Este artículo tiene como objetivo discutir la aplicación de la teoría del aprendizaje significativo al desarrollo de buenas prácticas docentes en la educación empresarial. Se realizó una investigación cualitativa, a partir de una revisión descriptiva de la literatura, que reveló estructuras y tendencias en cuanto a la aplicabilidad de los supuestos teóricos del aprendizaje significativo en los procesos de enseñanza y aprendizaje en las empresas. Los resultados indican que, para que ocurra un aprendizaje significativo en la educación corporativa, es necesario que los procesos didácticos en las empresas sean más inclusivos en relación a los nuevos conocimientos, considerando la importancia del conocimiento previo de las personas.

Palabras clave: Educación empresarial; Aprendizaje significativo; Estructura cognitiva; Conocimiento previo.

\section{INTRODUÇÃO}

A educação corporativa tem trazido avanços significativos para as empresas brasileiras. Ela tem se tornado mais inclusiva e mais flexível, principalmente devido a parcerias e soluções de ensino e aprendizagem (que podem ser empregadas em tempo e espaço diversos), a fim de viabilizar o alinhamento entre as atividades educacionais e as metas estratégicas das empresas. Esse alinhamento estratégico das organizações firmas com a educação corporativa tem evoluído com o passar dos anos. Entretanto, uma parte considerável das empresas brasileiras ainda não embasa suas ações em habilidades e competências estratégicas, provocando desarmonia entre as necessidades dos negócios e as atividades realizadas no âmbito corporativo (EBOLI, 2016).

Este trabalho demonstra sua relevância no contexto dos investimentos que as empresas devem fazer tanto para superarem crises quanto para sobreviverem e progredirem na sociedade atual. É necessário que as empresas jamais deixem de investir nas pessoas (formando seus líderes, educadores, inovadores e até mesmo empreendedores), na educação e na pesquisa e desenvolvimento (P\&D). No Brasil, esses investimentos precisam ser incrementados, para que a educação corporativa alcance reconhecimento nas organizações e para que ela continue se aperfeiçoando e se disseminando, visto que é uma forte aliada no desenvolvimento e uso de novos produtos e serviços, bem como confere às empresas a competitividade necessária para superar desafios (EBOLI, 2016).

Considerando o espaço ainda existente para a evolução dos processos de ensino e aprendizagem nas empresas brasileiras, bem como os desafios impostos a essas organizações, é necessário refletir sobre como a aprendizagem pode ser um elemento significativo para que a educação corporativa traga vantagens para as pessoas (colaboradores, gestores, líderes etc.) e para as organizações, de modo a despertar o interesse da sociedade pela educação nas empresas.

Nesse contexto, propõe-se como questão motivadora a possibilidade de que a teoria da aprendizagem significativa de Ausubel (2001) possa fornecer referenciais para boas práticas de ensino e aprendizagem na educação corporativa. A partir dessa problematização, o objetivo geral deste trabalho é discutir a aplicabilidade dos pressupostos teóricos da aprendizagem significativa na educação corporativa.

Como objetivos específicos, o trabalho procurou abordar a educação corporativa, descrever os principais pressupostos teóricos da aprendizagem significativa e discutir a aplicabilidade desses referenciais nas atividades didáticas da educação nas empresas. 
A fim de alcançar os objetivos expostos, a pesquisa partiu de uma revisão descritiva dos assuntos abordados a partir de textos acadêmicos que propiciassem um conhecimento mais amplo e mais profundo sobre conceitos e relações que pudessem contribuir para a discussão proposta. Os métodos adotados possibilitaram uma estruturação lógica e concatenada das informações produzidas.

O trabalho está estruturado de modo a contribuir para um maior entendimento sobre a educação corporativa, passando-se para a descrição dos elementos principais da teoria ausubeliana sobre a aprendizagem e possibilitando o exame da questão motivadora do trabalho. As considerações finais apontam que a teoria da aprendizagem significativa contém elementos de grande relevância para que os educadores no âmbito das empresas possam desenvolver atividades didáticas que estimulem maior aderência, aceitação e participação dos colaboradores, de modo a trazer benefícios tanto para as pessoas quanto para as empresas.

\section{METODOLOGIA}

As informações contidas neste trabalho constituem uma pesquisa aplicada, com o propósito de gerar conhecimentos com possibilidades de serem postos em prática no ambiente corporativo. Com isto, procurou-se estruturar um material que fomentasse a análise, a reflexão, a avaliação e a aplicação dos assuntos abordados (MEDEIROS, 2006).

Para alcançar conhecimento prévio sobre os assuntos em questão, foi executada uma revisão descritiva da literatura, para buscar um conjunto de informações na área da educação corporativa, a fim de apoiar ou revelar estruturas e tendências a respeito da aplicabilidade da teoria da aprendizagem significativa nos processos de ensino e aprendizagem nas empresas (PARÉ, 2015).

A abordagem qualitativa de pesquisa foi adotada com a finalidade de compreender e aprofundar os fenômenos explorados. Buscou-se, com esse enfoque, aprofundar perspectivas, opiniões e significados sobre a realidade da educação nas empresas brasileiras (SAMPIERI; COLLADO; LUCIO, 2013).

O procedimento de coleta foi a leitura exploratória de textos acadêmicos selecionados por meio da internet, os quais serviram de base para a revisão descritiva. Isto permitiu a conveniência do acesso às informações, a economia tanto de tempo para a pesquisa quanto de despesas com as transcrições das informações coletadas. Essa forma de coleta também propiciou a discussão dos tópicos abordados, por meio da análise de dados e da extração de sentidos dos textos, o que viabilizou uma interpretação do significado mais amplo dos dados e das suas relações (CRESWELL, 2007).

\section{EDUCAÇÃO CORPORATIVA}

A dinâmica da competitividade no mundo atual exige velocidade de aprendizado das pessoas e capacidade de gerir conhecimento das organizações. O conhecimento, criado e compartilhado tanto entre os colaboradores de uma determinada empresa quanto entre empresas, e até mesmo entre empresas e instituições de tipos variados (escolas, universidades, sindicatos, ONGs etc.), precisa ser devidamente gerido e explorado por profissionais que possuam competência para contribuir de forma eficiente com a interação entre os diversos entes que integram as redes nas quais os saberes podem ser disseminados (AIRES; FREIRE; SOUZA, 2017). 
Justamente essa interação entre os diversos entes (pessoas, empresas e outras instituições) gera uma extensa gama de conhecimentos que precisam ser identificados, estruturados, armazenados, processados e aplicados. Isto possibilita que novos conhecimentos sejam então produzidos, o que pode corroborar a constituição das vantagens competitivas e sustentáveis das empresas (AIRES; FREIRE; SOUZA, 2017).

Os novos conhecimentos produzidos no âmbito corporativo podem ser tácitos (não declarados, mas subentendidos pelos colaboradores) ou explícitos (manifestos e devidamente estruturados para serem disseminados e aplicados). Existem quatro maneiras por meio das quais o conhecimento passa de tácito a explícito: socialização, externalização, combinação e internalização. Essas formas de transformação do conhecimento compõem uma espiral, a qual gera valores e vantagens competitivas sustentáveis. Essa espiral do conhecimento demanda que os processos empresariais e as estratégias competitivas sejam integrados. Isso requer integração de pessoas, combinação de redes de comunicação e utilização de tecnologias da informação (AIRES; FREIRE; SOUZA, 2017). Esses elementos podem ser combinados por meio de práticas de ensino e aprendizagem nas empresas - a educação corporativa.

\subsection{Conceito de educação corporativa}

O conjunto de práticas educacionais que as empresas promovem com vistas a fomentar o desenvolvimento e o estabelecimento de competências (organizacionais e humanas) julgadas críticas para viabilizar as estratégias de negócios, é denominado educação corporativa (AIRES; FREIRE; SOUZA, 2017). Ela é descrita como a educação contínua dos profissionais e como o desenvolvimento de suas aptidões, estando estas alinhadas com os objetivos que as empresas almejam alcançar (WELTER; VIEIRA, 2019).

Esse conceito tem sido tratado desde meados do século XX, tendo-se consolidado nas décadas 19801990 e nos primeiros anos do século XXI, fortemente concentrado no Treinamento e Desenvolvimento (T\&D) dos funcionários das firmas. Ao longo dos anos, a educação corporativa vem evoluindo sob diferentes perspectivas didáticas e com a crescente aplicação de recursos digitais, na busca de satisfazer as expectativas de aprendizagem dos profissionais e as demandas de um mercado com tendências de maiores exigências e de multidisciplinaridade (WELTER; VIEIRA, 2019).

Em consequência à hipercompetitivade mundial, as empresas perceberam que as instituições de ensino formal (escolas e universidades) não proviam os egressos dos cursos tradicionais com a formação que estes precisavam para desempenhar suas funções, bem como para atender aos anseios dos diversos atores do mercado de trabalho (clientes, fornecedores e gestores). Por isso, as organizações passaram a se encarregar da capacitação de seus colaboradores, a fim de alcançar maior qualidade de formação profissional (AIRES; FREIRE; SOUZA, 2017).

Os componentes da qualidade da formação emergem das peculiaridades do capital humano, ou seja, das competências dos profissionais. Fatores como a preferência por constituir reservas internas de recursos financeiros e por potencializar o retorno dos custos com formação e qualificação são relevantes quando se consideram as pressões das condições de negócios e as dificuldades de acesso a fontes externas de recursos financeiros para as empresas. Nesse ambiente, a composição do quadro de pessoal por indivíduos competentes e produtivos é uma característica importante para a garantia da estabilidade das empresas (BURYAKOV et al., 2019). 
Nos países desenvolvidos, uma grande parte das empresas dedica esforços voltados ao desenvolvimento da educação corporativa. Nos Estados Unidos, por exemplo, apresentam-se três modelos de educação nas empresas (HARASHCHENKO et al., 2019), conforme pode ser visto no Quadro 1:

Quadro 1 - Modelos de educação corporativa nos EUA.

\begin{tabular}{|c|l|}
\hline Modelo & \multicolumn{1}{|c|}{ Descrição } \\
\hline Interno & $\begin{array}{l}\text { A empresa tem colaboradores responsáveis por desenvolver currículos e } \\
\text { cursos, bem como por treinar os demais colegas. }\end{array}$ \\
\hline Terceirizado & $\begin{array}{l}\text { A empresa adquire grande parte dos serviços educacionais de um ou mais } \\
\text { fornecedores. Uma equipe reduzida de gestores é responsável pelo } \\
\text { treinamento. }\end{array}$ \\
\hline Híbrido & $\begin{array}{l}\text { Uma parte das atividades educacionais é realizada pela empresa e outra parte } \\
\text { dessas atividades é realizada por terceiros. }\end{array}$ \\
\hline
\end{tabular}

Fonte: Autores.

Comparando-se os três modelos apresentados no Quadro 1, percebe-se que os provedores externos são menos demandados (quando o são) no modelo interno de educação corporativa. Já o modelo terceirizado possibilita que a empresa possa contar com a expertise de fornecedores para planejar, desenvolver e implementar todas as atividades educacionais. O modelo híbrido, por sua vez, possibilita a esforço conjunto das empresas e de seus fornecedores, o que viabiliza, por exemplo, o desenvolvimento do currículo pelos gestores da empresa e o desenvolvimento dos cursos e das atividades didáticas por terceiros.

Esse último modelo também torna viável o emprego de sistemas e recursos internos da empresa em treinamentos básicos, enquanto treinamentos avançados dos gestores podem ser completamente concretizados por provedores externos (HARASHCHENKO et al., 2019). Independentemente do modelo adotado pelas empresas, existem aspectos que potencializam os benefícios advindos da educação corporativa para as pessoas e para as empresas. Isso será abordado a seguir.

\subsection{Pontos-chave para boas práticas de educação corporativa}

Dentre os aspectos mais relevantes para o alcance dos objetivos estratégicos das empresas por meio da educação corporativa está o comprometimento pessoal dos colaboradores com a missão da organização à qual pertencem. Esse compromisso das pessoas viabiliza a proposição e o compartilhamento de ideias e perspectivas que fomentam a inovação nos processos de gestão e na produtividade das organizações (AIRES; FREIRE; SOUZA, 2017).

Um outro ponto relacionado ao comprometimento dos colaboradores é o interesse dos líderes no desenvolvimento das pessoas que compõem as equipes de trabalho. Para que as empresas possam se tornar uma organização que aprende, é necessário que os líderes assumam diversos papéis em relação à educação corporativa, tais como: patrocinador, comunicador, professor e gestor. Esses papéis devem ser cada vez melhor desempenhados para que o ensino e a aprendizagem nas empresas produza resultados satisfatórios (EBOLI, 2016).

Mais uma característica que influencia o ensino e a aprendizagem no âmbito corporativo é o modelo de aprendizagem. $\mathrm{O}$ emprego de tarefas desafiadoras, de treinamentos práticos, de desenvolvimento de projetos e de atividades voltadas aos relacionamentos interpessoais são exemplos de métodos 
que podem tornar a educação corporativa mais atraente e enriquecedora. Metodologias inovadoras estão cada vez mais presentes nas atividades educativas nas empresas, mas os métodos formais ainda são preponderantes. Por isso, a intensa participação dos líderes é novamente apontada como fator condicionante para que desafios e relacionamentos tenham maior impacto no desenvolvimento de habilidades e competências dos colaboradores (EBOLI, 2016).

Outro modelo que vem sendo incrementado na educação corporativa é a Educação a Distância (EaD). A flexibilidade de acesso, a redução de custos logísticos e a maior abrangência da área geográfica alcançada são as principais razões para o emprego dessa modalidade de ensino. As organizações que adotam a EaD podem fazer uso de diversos recursos síncronos (como videoaulas e videoconferências) e assíncronos (como e-mails e murais virtuais). Além desses, ainda há outros meios disponíveis que apresentam forte potencial para a aprendizagem nas organizações. Dentre eles, destacam-se: games, mobile learning, realidade virtual, simuladores e webinars. O EaD aplicado à educação corporativa é, de fato, uma tendência, embora ainda haja muitos programas em formato exclusivamente presencial (EBOLI, 2016).

O aprendizado tecnológico é uma tendência que se combina com o crescente emprego da educação corporativa no formato EaD. O uso cada vez mais amplo do e-learning combinado com recentes plataformas móveis e com o armazenamento em nuvem demandam o treinamento dos instrutores para lidarem de forma mais proveitosa com as ferramentas virtuais. Essa tecnologização dos processos de ensino e aprendizagem nas empresas, quando implementada de maneira adequada, tendem a causar uma queda contínua no percentual do tempo destinado às atividades didáticas em comparação aos treinamentos presenciais nos formatos tradicionais (HARASHCHENKO et al., 2019).

Os pontos-chave até aqui descritos são os catalisadores dos benefícios que a educação corporativa pode trazer, tanto para os indivíduos que compõem os quadros funcionais das empresas quanto para as próprias organizações. Esses resultados vantajosos serão abordados adiante.

\subsection{Vantagens da educação corporativa}

Os processos de educação nas empresas estão relacionados ao desenvolvimento de competências, o que fomenta o progresso da carreira das pessoas, associando-o à gestão das organizações em que elas atuam. A abordagem com base em competências contribui para o crescimento do capital humano das empresas, visto que representa uma reunião de técnicas de gestão de pessoal e de gestão de conhecimento. Essa combinação pondera o comportamento das pessoas em suas atividades profissionais, em termo de manifestação e aplicação de suas competências. Com isso, a correlação entre as competências e a eficiência dos profissionais se torna relevante para o sucesso das pessoas e das organizações em que elas exercem suas funções (BURYAKOV et al., 2019).

O sucesso de uma empresa também é influenciado por sua estabilidade financeira, a qual pode ser alcançada por meio da educação corporativa. Sendo o objetivo fundamental da educação nas empresas a formação de um modelo sustentável de desenvolvimento organizacional, com base nos valores e na filosofia de negócios da firma, a educação corporativa permite a transmissão de sua visão estratégica a todos os seus colaboradores e gestores, em todos os níveis de atuação desses profissionais. As mudanças na gestão organizacional e financeira da empresa precisam primeiro acontecer na mente dos indivíduos. Apoiada em processos de ensino e aprendizagem, a direção de uma organização corporativa pode difundir a compreensão sobre a essência e a necessidade de mudanças dentre todos os profissionais em todos os seus níveis de atuação (BURYAKOV et al., 2019). 
A disseminação do conhecimento dentro das empresas é um fator que confere a estas maior competitividade de mercado no contexto do mercado atual. As dinâmicas próprias do sistema capitalista apresentam inúmeros desafios às organizações, que precisam constantemente se reinventar para garantirem sua sobrevivência e competitividade frente a suas congêneres. Sendo assim, os investimentos em educação corporativa passam a ser estratégicos e vitais para a perenidade e o progresso das empresas (AIRES; FREIRE; SOUZA, 2017).

A economia globalizada, inegavelmente competitiva, demanda ciclos cada vez mais curtos para a criação de produtos. Neste contexto, as organizações se destacam pelo conhecimento que produzem e pelo modo como empregam esse conhecimento, para potencializar o aumento de produtividade e distribuição. Como consequência, a educação corporativa fomenta o uso do conhecimento das empresas para que essas tomem melhores decisões de marketing, produção, vendas e distribuição. Novamente, as práticas de ensino e aprendizagem das organizações trazem maiores vantagens competitivas (AIRES; FREIRE; SOUZA, 2017).

Essa primazia justifica os investimentos em educação corporativa como forma de superar os períodos de crise. Por um lado, ela traz resultados internos significativos, como melhoria do desempenho dos profissionais, aumento da satisfação dos colaboradores, maior orgulho das pessoas por integrarem a organização, aprimoramento dos processos da empresa e formação em maior quantidade e qualidade de novos líderes. Por outro lado, as consequências externas são muito sensíveis - aumento na qualidade dos produtos, dos serviços e do atendimento, bem como melhoria da imagem institucional e maior atração de talentos (EBOLI, 2016).

Os investimentos das empresas em capacitação não apenas propiciam o desenvolvimento de seus profissionais, mas também fomentam a transmissão cultural dessas organizações. Empresas inovadoras que mantêm os investimentos em educação mesmo em momentos de crise, tendem a consolidar uma cultura de empreendedorismo, pois conseguem comunicar sua visão de futuro e seus propósitos, tornando-se polos de disseminação de sua cultura e de formação de líderes por meio de sistemas bem estabelecidos de desenvolvimento de pessoas (EBOLI, 2016). Sobre a importância do capital humano, tem-se que:

O capital humano representa o conhecimento, as aptidões e as habilidades das pessoas, com a ajuda das quais eles criam riqueza pessoal, social e econômica. $\mathrm{Na}$ economia moderna, a riqueza nacional está gradualmente mudando de capital físico para humano, que está se tornando um recurso cada vez mais importante para o crescimento econômico [tradução nossa] (BURYAKOV et al., 2019, p. 11).

Deste modo, a importância do desenvolvimento do capital humano na economia moderna traz benefícios para as pessoas, para as organizações e para a riqueza nacional. O bem-estar dos países é determinado pelo estado de seus respectivos capitais humanos. Esse capital impulsiona a criação da riqueza pessoal, social e econômica. Portanto, a busca de modelos de educação corporativa para o desenvolvimento do capital humano precisa considerar as experiências bem-sucedidas já existentes. Sistemas de educação que fazem frente a todos os desafios modernos não existem. Por isso, há espaço para que as empresas implementem novos modelos de ensino e aprendizagem. Um país que possa contar com organizações detentoras de modelos modernos e eficazes de desenvolvimento de capital humano terá inúmeras vantagens no cenário do mundo pós-industrial e hipercompetitivo (BURYAKOV et al., 2019). 
Após esse enfoque dado à educação corporativa, é possível passar para algumas considerações sobre os principais pressupostos teóricos da teoria da aprendizagem significativa para subsidiar reflexões mais profundas sobre a educação nas empresas.

\section{APRENDIZAGEM SIGNIFICATIVA}

Segundo Ausubel (2001), aprendizagem significativa implica aquisição de novos significados com base em algum material de aprendizagem potencialmente significativo para o aprendiz. Isto pressupõe que o material de aprendizagem precisa estar relacionado com uma estrutura cognitiva (do aprendiz) relevante e apropriada, e que essa estrutura cognitiva particular contenha ideias com as quais o material de aprendizagem possa se relacionar. Novos significados (verdadeiros ou psicológicos) surgem então da influência recíproca entre as ideias relevantes na estrutura cognitiva do aprendiz e os significados potenciais do material de aprendizagem. Uma vez que a estrutura cognitiva de cada indivíduo é única, todos os novos significados adquiridos pelo aprendiz são únicos necessariamente.

As ideias expressas simbolicamente interagem de modo não-literal (não ao pé da letra) e nãoarbitrário (não com qualquer ideia prévia). Tais ideias se relacionam mutuamente com algum conhecimento já existente na estrutura cognitiva do indivíduo que aprende. Por isso, os materiais devem ser relacionáveis a conhecimentos específicos, os quais o aprendiz deve possuir para construir relacionamentos apropriados (MOREIRA, 2011).

A reciprocidade entre novos conhecimentos e conhecimentos prévios exige que duas condições sejam atendidas: que o material de aprendizagem seja potencialmente significativo e que o indivíduo que aprende demonstre predisposição para a aprendizagem, visto que a vontade de relacionar os novos conhecimentos deve partir do aprendiz (MOREIRA, 2011).

À luz da teoria ausbeliana da aprendizagem significativa, o principal fator que afeta a aprendizagem e a retenção de novos conhecimentos pelo aprendiz são os seus conhecimentos prévios e a organização hierárquica destes. Clareza, estabilidade e organização dos conhecimentos prévios é o que mais exerce influência sobre a aquisição significativa de novos conhecimentos. Isso torna viável processos interativos nos quais aquilo que é novo ao aprendiz ganha significação, passando por integrações e diferenciações em relação àquilo que já existe em sua estrutura cognitiva. O que já existe nessa estrutura recebe novos significados, com maior estabilidade, diferenciação, profundidade e capacidade de ancorar novos conhecimentos (MOREIRA, 2011).

Essa ancoragem metafórica exige que certas ideias-âncora (conhecimentos pré-existentes) possam se ligar a novos conhecimentos, para que estes venham a adquirir significados. Essas ideias-âncora (ideias subordinantes) são denominadas subsunçores, e o processo de ancoragem entre as informações prévias e as novas é o processo de subsunção (AUSUBEL, 2001). Entretanto, os subsunçores não possuem um caráter imutável. Visto que a subsunção é um processo interativo e dinâmico, a ancoragem entre o já existente e o que a ele se acrescenta pode modificar os próprios subsunçores (MOREIRA, 2011).

$\mathrm{Na}$ ausência de subsunçores adequados para a ancoragem e a atribuição de significados aos novos conhecimentos, é possível que o instrutor empregue um recurso instrucional dotado de níveis mais altos de abstração, generalidade e inclusividade em relação ao material de aprendizagem. Esse recurso é denominado organizador prévio. Organizadores prévios podem ser: enunciados, perguntas, 
situações-problema, demonstrações, filmes, leituras introdutivas, simulações, ou até mesmo aulas que precedem uma sequência de outras aulas (MOREIRA, 2011).

Considerando que cada indivíduo possui uma estrutura cognitiva (idiossincrática de certo modo), os organizadores prévios devem apresentar níveis mais elevados de abstração, generalidade e inclusão em relação aos materiais de aprendizagem, para que possam produzir os efeitos dos quais se esperam para diversos aprendizes, quais sejam: permitir o fornecimento e/ou a alteração de ideias ancoradas em nível subordinante aos aprendizes (AUSUBEL, 2001). Em suma, organizadores prévios são recursos que podem suprir a deficiência de subsunçores, ou, ainda, possibilitam identificar a racionalidade e a discriminabilidade entre os novos conhecimentos e os já existentes, ou seja, os subsunçores (MOREIRA, 2011). A maneira como os subsunçores, ou, na sua ausência, os organizadores prévios são empregados fazem com que a aprendizagem de novos conhecimentos possa ocorrer de maneiras distintas.

A aprendizagem mecânica, por exemplo, é a que ocorre com maior frequência. Ela é puramente memorística, sem significado, e serve apenas para a realização de provas, sendo esquecida logo em seguida. Essa aprendizagem é a coloquialmente chamada de decoreba, muito utilizada por aprendizes e também muito incentivada por instrutores (MOREIRA, 2011). Aprendizagem memorística pode até se relacionar com a estrutura cognitiva do aprendiz, porém apenas de forma arbitrária e literal, o que impede a aquisição de novos significados (AUSUBEL, 2001).

Contudo, a aprendizagem significativa e a aprendizagem por memorização não são dicotômicas. Em muitas situações de ensino e aprendizagem, elas podem se apresentar num espectro contínuo de memorização e significado (AUSUBEL, 2001, p. 5). Existe, portanto, uma região cinza entre esses dois polos, conforme se pode verificar na Figura 1:

Figura 1 - Continuidade entre a aprendizagem mecânica e a aprendizagem significativa.

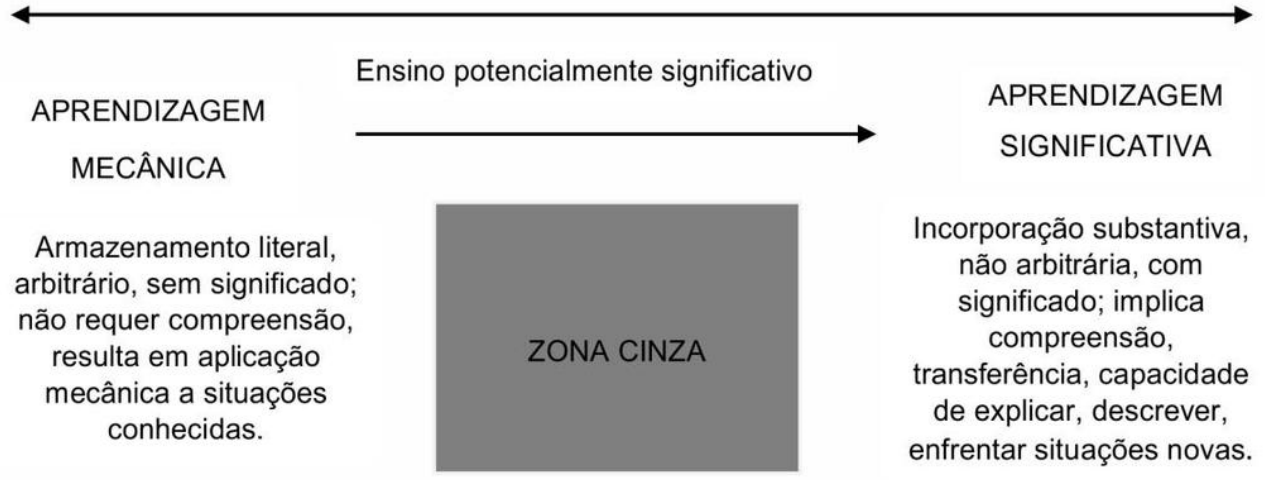

Fonte: Moreira (2011, p. 32).

Sobre o contínuo entre a aprendizagem mecânica e a significativa, representado na Figura 1, são necessárias algumas considerações. De acordo com Moreira (2011), não é natural a passagem da aprendizagem mecânica para a aprendizagem significativa. A aprendizagem significativa é progressiva, sendo o processo de construção dos subsunçores algo não imediato. Essa aprendizagem demanda a captação de significados - processo de negociação entre instrutor e aprendiz, o qual pode durar muito tempo. Nessa dialética, situações-problema trazem sentido aos conceitos, à proporção que o aprendiz domina situações cada vez mais complexas, o que também confere caráter processual à aprendizagem significativa. 
Outras distinções entre o modo como ocorre a aprendizagem são: aprendizagem receptiva e aprendizagem por descoberta. Na aprendizagem receptiva, o aprendiz é receptor da informação, do conhecimento a ser aprendido, em sua forma final. Isso, contudo, não quer dizer que essa aprendizagem seja algo passivo, muito menos que esteja necessariamente associada ao ensino expositivo, tradicional. Aprender receptivamente implica que o aprendiz não precisa descobrir para que ocorra a aprendizagem. Outra razão pela qual a aprendizagem receptiva não pode ser encarada como passiva é o fato de que a aprendizagem significativa requer muita atividade cognitiva da parte dos aprendizes, necessária para estabelecer relações e interações entre novos conhecimentos e aqueles já existentes em sua estrutura cognitiva (MOREIRA, 2011).

Já com a aprendizagem por descoberta, o aprendiz primeiramente descobre aquilo que vai aprender. Uma vez descobertas as novas informações, as condições para a aprendizagem significativa são novamente o conhecimento prévio adequado e a predisposição para aprender. É importante compreender que a aprendizagem por descoberta não implica necessariamente aprendizagem significativa. Adultos (até mesmo crianças não tão pequenas) aprendem por recepção e pela interação cognitiva entre os conhecimentos prévios e recebidos basicamente. Se as pessoas tivessem que descobrir a grande quantidade de informações existentes no mundo atual para que pudessem então aprendê-las, a aprendizagem significativa seria inexequível (MOREIRA, 2011).

O que viabiliza a aprendizagem significativa e o processo de resolução de problemas é o envolvimento sucessivo da aprendizagem por recepção e da aprendizagem por descoberta (AUSUBEL, 2001). Outra metodologia, que está situada entre a recepção e a descoberta é a aprendizagem por descoberta dirigida, muito adequada para a condução de experimentos, por exemplo (MOREIRA, 2011).

A aprendizagem pode ocorrer, portanto, de diversas maneiras, mas nenhuma delas impede que haja o esquecimento daquilo que se aprendeu, haja vista ser o esquecimento uma consequência natural da aprendizagem significativa. Ausubel (de acordo com MOREIRA, 2011) denominava como assimilação obliteradora a perda progressiva da dissociação entre novos conhecimentos em relação àqueles subsunçores que lhes possibilitaram a ancoragem cognitiva.

Embora haja uma diminuição progressiva quando um conhecimento não é empregado durante muito tempo, a aprendizagem significativa proporciona ao indivíduo uma sensação agradável de que é possível reaprender esse mesmo conhecimento em um período de tempo relativamente curto e sem grandes dificuldades. Do contrário, se a aprendizagem tiver sido mecânica, a sensação ruim, de desperdício de tempo, é a de que esse mesmo conhecimento não fora de fato aprendido, não havendo sentido em se falar, pois, em reaprendizagem (MOREIRA, 2011).

Sendo assim, a primazia da aprendizagem significativa frente à mecânica se reflete em aspectos, tais como compreensão, significado e capacidade de transferir conhecimento para situações novas. Em momento posterior, o proveito se revela na maior retenção e na viabilização da reaprendizagem (a qual praticamente é impossível se a aprendizagem for mecânica), em tempo muito menor do que o necessário para a aprendizagem inicial (MOREIRA, 2011).

A partir das abordagens sobre a educação corporativa e da descrição dos elementos teóricos da aprendizagem significativa, é possível então passar para a discussão sobre a viabilidade de aplicar esses referenciais para fomentar as boas práticas de educação nas empresas. 


\section{DISCUSSÃO}

As empresas têm o papel de criar condições para que haja transferência de informações entre seus gestores e colaboradores. Empresas são como organismos vivos, possuindo personalidade e características próprias, algo que não pode ser ignorado. Nessas organizações, os funcionários, por meio de sua atuação, são responsáveis (diretamente ou não) pelos resultados da firma, o que evidencia a relevância dos processos de treinamento e capacitação nas empresas - a educação corporativa (VIRGENS; FRANÇA, 2018).

No contexto da educação corporativa, considerando-se o conceito de subsunção da teoria ausubeliana da aprendizagem significativa, se um colaborador possui algum conhecimento prévio sobre os assuntos abordados nas atividades de ensino da organização, sua aprendizagem pode ser facilitada. Isto ocorre porque a proposta ou o assunto a ser ensinado pode já contar com algum significado para o aprendiz integrante do capital humano da firma, o que torna mais eficiente sua construção de novos significados para a formação do conhecimento considerado importante para o sucesso da empresa em que atua (ROSSINI; LOPES, 2016).

Como posto por Moreira (2011), diversos fatores influenciam a aprendizagem, sendo que a estrutura cognitiva prévia (conceitos, proposições, esquemas mentais etc.), ou seja, os conhecimentos prévios hierarquicamente organizados do indivíduo compõem a variável mais importante isoladamente. $A$ aprendizagem significativa só ocorre, portanto, quando o aprendiz consegue apreender o objeto ensinado, relacionando-o com seus projetos pessoais. No âmbito da educação corporativa, o instrutor deve ajudar o aprendiz (um funcionário, neste caso) a identificar e tratar de questões que façam sentido para si (VIRGENS; FRANÇA, 2018).

Além do corolário imediato de que qualquer intenção didática para facilitar a aprendizagem deve partir do conhecimento prévio do aprendiz, outra premissa desponta a partir disso: o sujeito que aprende vai diferenciando de modo progressivo, reconciliando simultânea e integrativamente, os novos conhecimentos, ancorados àqueles que já possui. Por isso, a facilitação da aprendizagem na educação corporativa deveria usar tais ideias-âncora como princípios programáticos dos conteúdos a serem ensinados (MOREIRA, 2011).

Os responsáveis pelo planejamento do conteúdo curricular das atividades de ensino nas empresas precisam mapear conceitualmente esse currículo. Isto permite a identificação de ideias mais gerais e mais inclusivas, bem como o reconhecimento de conceitos estruturantes e de proposições-chave daquilo que será ensinado. Ou seja, analisar os conteúdos a serem ensinados possibilita diferenciar o que é importante do que é secundário para o desenvolvimento dos funcionários de uma empresa. Após esse planejamento, uma vez que os conceitos e proposições mais gerais e inclusivos tenham sido apresentados aos instruendos, tais elementos devem ser exemplificados e trabalhados em situações de ensino imediatamente, a fim de propiciar a aprendizagem significativa (MOREIRA, 2011).

Ainda tratando da facilitação da aprendizagem significativa, há que se considerar a importância dos organizadores prévios. Já que esses recursos são materiais introdutórios formulados de acordo com o conhecimento que o aprendiz tem ou precisa ter para lidar de maneira mais eficaz com os novos conhecimentos, os organizadores prévios fariam a ponte cognitiva entre esses conhecimentos e aqueles que o funcionário deveria ter para que os materiais de aprendizagem possam ser potencialmente significativos no contexto organizacional. Outra situação em que esses organizadores são muito úteis à educação corporativa é quando o colaborador já possui conhecimentos prévios 
adequados, mas não é capaz de perceber por si só a maneira como as novas informações se relacionam com seus conhecimentos pré-existentes ou, ainda, como se diferenciam destes (MOREIRA, 2011).

É possível também discorrer sobre estratégias e instrumentos facilitadores da aprendizagem significativa na educação corporativa. Além dos organizadores prévios, os mapas conceituais (diagramas conceituais hierárquicos que destacam conceitos e relações entre eles) e os diagramas $\mathrm{V}$ (instrumentos heurísticos que enfatizam as interações entre o pensar e o fazer), por exemplo, também podem fomentar a aprendizagem significativa (MOREIRA, 2011) no âmbito organizacional.

As empresas também podem se valer das atividades colaborativas, presenciais e/ou virtuais e em grupos, para alavancar e facilitar a aprendizagem significativa. Essas atividades tornam possível o intercâmbio e a negociação de significados, o que exige que o instrutor exerça o papel de mediador, sem que, todavia, este não possa se valer de aulas expositivas tradicionais quando considerar necessárias para a aprendizagem dos colaboradores da organização (MOREIRA, 2011). Lidar com informação e troca de pontos de vista em um ambiente corporativo, com enfoque na liderança participativa e colaborativa por meio da aprendizagem ativa, preconiza a construção da liderança com as contribuições dos liderados e de suas experiências, com a mediação do líder na formação de novos conhecimentos relacionados às metas organizacionais da firma (ROSSINI; LOPES, 2016).

Na educação corporativa, um dos propósitos essenciais é o envolvimento dos colaboradores com questões que estejam alinhadas com a realidade de sua atuação profissional, por meio de atividades desenvolvidas em ambiente didático (sala de aula presencial ou virtual), haja vista que nem sempre é possível oferecer aos profissionais oportunidades de observação no campo em que atuam. As atividades didáticas nas empresas possibilitam análises diagnósticas de situações e integração entre teoria e prática. Essa forma significativa de aprendizagem resulta em benefícios para as pessoas e para as empresas, tornando possível uma conexão entre o colaborador-aprendiz e sua realidade profissional (VENDRAMIN; ARAUJO, 2020).

Por meio da contextualização, os profissionais conseguem entender com mais facilidade as questões que forem alvo das atividades didáticas no contexto organizacional. Por exemplo, ao perceber que deverá responder questões e resolver situações-problema baseadas na realidade da empresa e nas informações que estiverem sendo ensinadas, o indivíduo é estimulado a superar a mera memorização de conceitos, devendo demonstrar capacidade de apresentar suas próprias interpretações e análises (VENDRAMIN; ARAUJO, 2020).

Para um líder, descentralizar tarefas e valorizar seu colaborador como alguém capaz de criar e participar de propostas dentro de um grupo de trabalho são aspectos muito proveitosos. Já para um colaborador, fazer parte do processo e, mais que isso, criá-lo de modo colaborativo com ideias, experiências, capital intelectual etc., em situações de trabalho mais justas, dinâmicas e com resultados relevantes para o grupo de trabalho, também traz muitas vantagens. Compartilhar informações gera conhecimento, que poderá ser empregado nas ações previstas no planejamento estratégico da empresa e que, por meio da rede social formada pelos funcionários, será controlada por todos eles, consultada e disseminada em tempo real, de modo que cada profissional seja capaz de encontrar soluções para lidar com os desafios de suas atividades cotidianas (ROSSINI; LOPES, 2016, p. 160). 
Nessa rede social da empresa, a linguagem também é um aspecto relevante para facilitar a aprendizagem significativa por recepção e pela descoberta. Com a manipulação adequada de conceitos e proposições, por meio da conveniente utilização das palavras, bem como por meio do aperfeiçoamento da compreensão dos indivíduos que aprendem, os significados se tornam mais claros, mais precisos e mais facilmente negociáveis entre instrutores e aprendizes (AUSUBEL, 2001).

A troca de informações entre gestores, instrutores e colaboradores podem corroborar a aprendizagem significativa nas empresas. Ainda há um consenso entre muitos funcionários de que os treinamentos nas firmas são cansativos, e que não podem ser aplicados de modo prático em suas rotinas cotidianas de trabalho (VIRGENS; FRANÇA, 2018). A fim de superar essa percepção, pode-se adotar uma construção cognitiva de valores e conhecimentos organizacionais, com base em processos participativos e colaborativos, os quais venham a valorizar as experiências e as informações que possam tornar viáveis novas formas de trabalho entre líderes e liderados de uma empresa (ROSSINI; LOPES, 2016).

\section{CONSIDERAÇÕES FINAIS}

Na educação corporativa, assim como em qualquer outro tipo de sistema educacional, qualquer estratégia, instrumento, técnica ou método que empregue o enfoque comportamentalista do tipo certo/errado ou sim/não, bem como qualquer estratégia que implique copiar-memorizar-reproduzir, promoverá a aprendizagem mecânica, e não a aprendizagem significativa (MOREIRA, 2011).

Aprendizagem está ligada ao compartilhamento de informações entre líder/instrutor e colaborador/aprendiz, estimulado pelo desequilíbrio entre propostas de ensino e interesse em buscar respostas. Quando ambos (instrutor e aprendiz) chegam a um acordo, alcança-se o equilíbrio - o ensino e a aprendizagem. Essa interação no ambiente corporativo torna possível que o profissional aprenda e pessoa discutir suas ideias com seus instrutores, resultando em crescimento e desenvolvimento de ambas as partes (ROSSINI; LOPES, 2016).

O bom relacionamento entre líder e liderado é uma condição que torna promissoras as práticas de educação corporativa, pois sem o mínimo de simpatia entre eles é praticamente impossível promover qualquer construção significativa de conhecimento na estrutura cognitiva do educando (VENDRAMIN; ARAUJO, 2020).

De acordo com os preceitos da teoria da aprendizagem significativa, aprender mecanicamente é decorar e memorizar conceitos, enquanto aprender significativamente leva ao raciocínio crítico, visto que durante o processo, os conhecimentos passam a ter significado para o aprendiz. Assim, significados serão ancorados aos conceitos prévios do indivíduo e ele poderá utilizar esses significados para resolver problemas, conjugando aspectos teóricos e práticos em sua atividade profissional (VENDRAMIN; ARAUJO, 2016).

Compreender como ocorre o processo de aprendizagem é fundamental para a escolha de estratégias didáticas, bem como para sua aplicação e obtenção de resultados positivos para as pessoas e para as empresas e, por consequência, para a sociedade (VENDRAMIN; ARAUJO, 2020). Neste ínterim, ficam evidentes as transformações possíveis da rotina corporativa, tanto as positivas quanto as negativas, caso o colaborador incorpore ou não os conhecimentos apresentados por meio das práticas didáticas de educação corporativa, alcançando mais do que a compreensão da importância de cumprir 
regras e determinações, mas também se beneficiando da aprendizagem significativa (VIRGENS; FRANÇA, 2018).

Facilitar a aprendizagem significativa depende muito mais da postura do instrutor e das diretrizes da empresa do que de novos métodos de ensino, mesmo considerando os mais novos recursos tecnológicos de informação e comunicação (MOREIRA, 2011). Para que a educação corporativa seja um processo prazeroso e proporcione assimilação e progressos, o instrutor deve garantir as condições necessárias para que o aprendiz tenha interesse em aprender, para que possa entender os conceitos, e para que possa identificar, no seu ambiente de trabalho, como o que está sendo ensinado pode ser posto em prática (ROSSINI; LOPES, 2016).

Novas pesquisas podem questionar se os gestores e líderes, responsáveis geralmente por aplicar treinamentos nas empresas, veem a si próprios como instrutores, se identificam em si a necessidade de desenvolver competências para o ensinar, e ainda, se possuem domínio dos temas a serem abordados nas atividades de ensino e se possuem conhecimento do público-alvo e do contexto no qual o conhecimento deve ser inserido e tratado. É bem possível que a resposta a essas indagações seja não (VIRGENS; FRANÇA, 2018).

Para que a aprendizagem significativa possa de fato ocorrer na educação corporativa, os instrutores nesses sistemas de educação precisam saber como desafiar conceitos já aprendidos pelos indivíduos, de modo que estes possuam reconstruí-los de maneira mais ampliada e consistente, o que pode tornar os processos didáticos nas empresas mais inclusivos em relação a novos conhecimentos (VENDRAMIN; ARAUJO, 2020). Desta maneira, o enfoque da educação nas empresas deve ser a promoção de hábitos como buscar, pesquisar, elaborar e refletir, a fim de que haja um esforço consciente de líderes e liderados direcionado para a aprendizagem e para o desenvolvimento das pessoas e das organizações.

\section{REFERÊNCIAS}

AIRES, R. W. A.; FREIRE, P. S.; SOUZA, J. A. Educação corporativa como ferramenta para estimular a inovação nas organizações: uma revisão de literatura. In: VIEIRA, A. C. P.; ZILLI, J. C.; BRUCH, K. L. (Org.). Propriedade intelectual, desenvolvimento e inovação: ambiente institucional e organizações. Criciúma: EDIUNESC, 2017.

AUSUBEL, D. P. Aquisição e retenção de conhecimentos: uma perspectiva cognitiva. Lisboa: Plátano Edições Técnicas, 2001.

\section{BURYAKOV, G. A. et al. Corporate Education system as a factor of ensuring modern} companies' financial stability. International Journal of Economics and Business Administration, Volume VII, Special Issue 2, 2019.

CRESWELL, J. W. Projeto de pesquisa: métodos qualitativo, quantitativo e misto. Porto Alegre: Artmed, 2007.

EBOLI, M. Educação Corporativa nos novos cenários empresariais. GVEXECUTIVO, v. 15, n. 2, jul./dez. 2016.

HARASHCHENKO, L. et al. Models of corporate education in the United States of America. Journal of Entrepreneurship Education, Volume 22, Issue 3, 2019. 
MEDEIROS, J. B. Redação científica: a prática de fichamentos, resumos, resenhas. São Paulo: Atlas, 2006.

MOREIRA, M. A. Aprendizagem significativa: a teoria e textos complementares. São Paulo: Editora Livraria da Física, 2011.

PARÉ, G. et al. Synthesizing information systems knowledge: a typology of literature reviews. Information \& Management, vol. 52, n. 2, mar. 2015, p. 183-199.

ROSSINI, A.; LOPES, F. J. A aprendizagem ativa na formação de uma liderança participativa e democrática nas empresas. Augusto Guzzo Revista Acadêmica, n. 17, 2016.

SAMPIERI, R. H.; COLLADO, C. F.; LUCIO, M. P. B. Metodologia de pesquisa. Porto Alegre: Penso, 2013.

VENDRAMIN, E. O.; ARAUJO, A. M. P. A Teoria da Aprendizagem Significativa e a estratégia de ensino método do caso: um estudo no ensino superior de contabilidade introdutória. Revista GUAL, Florianópolis, v. 13, n. 1, p. 157-179, jan./abr. 2020.

VIRGENS, J. S.; FRANÇA, S. L. B. A importância da Aprendizagem Significativa na cultura de segurança do trabalhador operacional. Congresso Nacional de Excelência em Gestão, ISSN 1984-9354, 2018.

WELTER, M. Z. C. S.; VIEIRA, A. M. D. P. Educação a distância: o uso do e-learning na Educação Corporativa. Revista Educere Et Educare, vol. 15, n. 33, set./dez. 2019.

Submissão: 08/08/2021

Aceito: 18/08/2021 